\title{
Empirical Research and Practice-oriented Physics for the Humanities and Sciences
}

\author{
István Berszán \\ Babes-Bolyai University
}

Follow this and additional works at: https://docs.lib.purdue.edu/clcweb

Part of the Comparative Literature Commons, and the Physics Commons

Dedicated to the dissemination of scholarly and professional information, Purdue University Press selects, develops, and distributes quality resources in several key subject areas for which its parent university is famous, including business, technology, health, veterinary medicine, and other selected disciplines in the humanities and sciences.

CLCWeb: Comparative Literature and Culture, the peer-reviewed, full-text, and open-access learned journal in the humanities and social sciences, publishes new scholarship following tenets of the discipline of comparative literature and the field of cultural studies designated as "comparative cultural studies." Publications in the journal are indexed in the Annual Bibliography of English Language and Literature (Chadwyck-Healey), the Arts and Humanities Citation Index (Thomson Reuters ISI), the Humanities Index (Wilson), Humanities International Complete (EBSCO), the International Bibliography of the Modern Language Association of America, and Scopus (Elsevier). The journal is affiliated with the Purdue University Press monograph series of Books in Comparative Cultural Studies. Contact: <clcweb@purdue.edu>

\section{Recommended Citation}

Berszán, István. "Empirical Research and Practice-oriented Physics for the Humanities and Sciences." CLCWeb: Comparative Literature and Culture 18.2 (2016): <https://doi.org/10.7771/1481-4374.2860>

This text has been double-blind peer reviewed by $2+1$ experts in the field.

The above text, published by Purdue University Press @P Purdue University, has been downloaded 98 times as of 11/ $07 / 19$.

This document has been made available through Purdue e-Pubs, a service of the Purdue University Libraries. Please contact epubs@purdue.edu for additional information.

This is an Open Access journal. This means that it uses a funding model that does not charge readers or their institutions for access. Readers may freely read, download, copy, distribute, print, search, or link to the full texts of articles. This journal is covered under the CC BY-NC-ND license. 


\section{PURDUE}

UNIVERSITY PRESS <http://www.thepress.purdue.edu>

\section{CLCWeb: Comparative Literature and Culture}

ISSN 1481-4374 <http://docs.lib.purdue.edu/clcweb> Purdue University Press (CPurdue University

CLCWeb: Comparative Literature and Culture, the peer-reviewed, full-text, and open-access learned journal in the humanities and social sciences, publishes new scholarship following tenets of the discipline of comparative literature and the field of cultural studies designated as "comparative cultural studies." In addition to the publication of articles, the journal publishes review articles of scholarly books and publishes research material in its Library Series. Publications in the journal are indexed in the Annual Bibliography of English Language and Literature (ChadwyckHealey), the Arts and Humanities Citation Index (Thomson Reuters ISI), the Humanities Index (Wilson), Humanities International Complete (EBSCO), the International Bibliography of the Modern Language Association of America, and Scopus (Elsevier). The journal is affiliated with the Purdue University Press monograph series of Books in Comparative Cultural Studies. Contact: <clcweb@purdue.edu>

\section{Volume 18 Issue 3 (September 2016) Article 2 István Berszán, "Empirical Research and Practice-oriented Physics for the Humanities and Sciences" <http://docs.lib.purdue.edu/clcweb/vol18/iss2/2>}

Contents of CLCWeb: Comparative Literature and Culture 18.2 (2016) Thematic Issue New Work in the Empirical Study of Literature. Ed. Aldo Nemesio <http://docs.lib.purdue.edu/clcweb/vol18/iss2/>

Abstract: In his article "Empirical Research and Practice-oriented Physics for the Humanities and Sciences" István Berszán proposes an empirical approach for the humanities and sciences he designates as "practice-oriented physics." He bases his argumentation on Albert-László Barabási's network theory applied and question tenets of complexity, networks, and spaces. Further, Berszán elaborates on the affinity between the spaces of practical orientation and the spaciousness of parallel worlds as explicated in Brian Green's string theory. Berszán posits that because the universe as "symphony" of string oscillations leads to parallel rhythms of happenings and their different spaces of motion and argues that this kind of "complicacy" of spaciousness cannot be analyzed with the use of network models. 


\section{István BERSZÁN}

\section{Empirical Research and Practice-oriented Physics for the Humanities and Sciences}

Do all things happen in the same complex space or do we have to deal with a multitude of spaces? My argumentation to respond to these questions proceeds along the following questions: 1) How scholars of the humanities include physics in the study of literature, 2) The narrowness of network spaces, 3) Analogies and affinities between empirical research and string theory, 4) The hither and thither side of analogy, 5) The topicality of Plato's cave experiment, 6) Rhythmic dimensions and time projections, and 7) Toward the experiments of practice-oriented physics.

1) How scholars of the humanities include physics in the study of literature: what can be there where there is no text nor context, but there still seems to be literature. What is left is thus the very thing practical research is focused on: extremely refined and intensive gestures of attention practiced in the time of literary reading and writing. These cannot be shepherded into the fold of interpretation because it would prove too narrow for them. Gestures of attention are more diverse than the approaches of interpretation. If we are really interested in following these gestures we have to get into their multiple kinetic spaces by practice. A "speechless tour" in the forest by night without a path to follow and without flashlights can dislodge us from our culturally dominant ways of paying attention (such as reflection or creating discursive relations) and may help us to reveal other ways with different rhythms: holding together in the dark forest, following a guide who most of the time cannot be seen at all, helping each other in getting through obstacles, keeping in touch with what is going on in the living forest. We enter the time or rhythm of literary reading and writing by the aid of similarly intensive rituals of attention. To read a poem or a piece of prose means in practice to get experienced in the gestures of attention they make us follow. Getting beyond literary criticism tailored on text and context, we can discover an essential link between multiple ways of paying attention, gestural resonance, and literary reading or writing (see Berszán, "Historical," "Irodalomfizika," "Rendszeridő"). Empirical research is more than a science focusing on the investigation of practical exercises. Practicing different rhythms becomes the main tool of investigation, which can complement critical approaches with experimental contact making. Critical practice seems to be insufficient both in human contact making and scientific research (and especially so when literary criticism is not empirical). The unavoidable distance of critical relation may be useful in observation, but it prevents us from approaching closely what we are searching for, as well as from getting close to those with whom we share our critical observations. Complementary alternative ways of establishing contacts make it possible for scientific research to discover (in artistic practices, for instance) that kinetic spaces of motion are much larger than certain given contexts. By its intensive multiple rhythms, practical research promotes an ethics conceived of as practical orientation in time(s) focusing on questions such as how can we get in touch with something that happens, how can we get into the rhythm of an event or into the space of a practice, how can we find a passage between the kinetic spaces of different occurrences? These questions are essential in completing empirical research on attention (see, e.g., Berszán, "Ismétlés-e"; Wu).

2) The narrowness of network spaces: by drawing a distinction between the mathematical space of graph theory and scale-free networks, Albert-László Barabási discovered the hidden pattern behind networks of our world. According to Barabási, it seems that almost everything from the cell to the internet, from social connection networks including our individual behavior to economic systems everything is linked to a network space where even human issues become calculable. Nevertheless, the scale-free network does not fill the whole of existing space: the practical density of connections, for instance, reduced by network theory to points and edges are surely outside of it. For calculable points and edges do not matter if there are biochemical reactions in question or clicking on favorite links or making friends. Further, Barabási does not take into account the practical orientation of research as a contact making attempt. Correlating the relations of points and edges to different happenings is acceptable only in mathematical calculations. Beyond its kinetic space, any kind of practical orientation including calculation does not occur in terms of points and edges but by intensive gestures of attention. Attention is neither a beam linking our eyes to the object nor merely the working of a substratum (the neural network). It cannot be reduced to our calculable habits either like our usual location at a given part of the day. Attention is always practical orientation in time(s) as well. This kinetic density or rhythm characterizing any behavioral movement is missing from the space of networks. There are much more things happening to people than their calculable "operation." The latter is, in fact, the operation of the network model, which-similarly to previous models like that of tabula rasa, mechanical machine, film-like memory or computer-constrain the multiple happenings of our lives into their narrow kinetic space until they are replaced by a new, more flexible model. Friedrich Kittler calls this the history of media and this is why I try elsewhere to reveal the narrowness of the concept of contextual complexity (Berszán, "Mediation"). Practical/empirical orientation is unavoidable exactly because of the excess of urges. They are manifold so that practical orientation can be hardly reduced to "operation" even in the conditions of a concentration or labor camp (see for instance Imre Kertész's Fatelessness or Herta Müller's The Hunger Angel).

Based on Barabási's investigations regarding our net surfing habits, we could hypothesize that our orientation in and among different kinetic spaces is describable by power-law distribution, since every one of us has his/her own important activities filling out the main part of time and other activities with a lower priority. However, practice cannot be replaced by statistic frequency. Scholars of network theory forget that there are spaces separated by "worlds" from one another, that multiple organization is not necessarily a complex network, and that it can mean multiple kinetic spaces as well. If we say that the world around us is auto-organized just as the internet is, we forget that the network-like feature is only one among some other "likenesses" in the case of reality (as in world-like, event-like, living-like or 
haphazard-like, etc.) and that these are not necessarily interconnected in a network-like manner. This is why I set the concept of spaciousness against the model of complex systems. The latter includes all occurrences into the same network space considering them as working according to common rules, whereas the former conception reveals heterogeneous or parallel worlds which may be governed by different rules. The kinetic spaces of practical/empirical corresponds to the extra-dimensions or the parallel universes of string theory (see Greene, Elegant, The Hidden) rather than to complex network systems where everything coheres with everything else. While according to Barabási interactions among cell proteins or the members of a society reveal the same pattern of scale-free networks, kinetic spaces investigated in empirical research resemble the spaciousness of string theory-as many vibration patterns as particles, power-transmitters or worlds which are not connected into a network, but differentiated by their rhythms. The universe as a diverse vibration symphony of strings does not only mean common operation, but parallel worlds transcending one another's spatiality. Beyond the pattern of network links between point-like locations we can discover spaciousness by crossing through practical distances between different rhythms of practice. This "complicatedness" of the kinetic spaces and that cannot be interpreted in terms of network models suggests that a different approach is applicable, namely "practice-oriented physics" (my term) in which spaciousness is opposed to complexity.

3) Analogies and affinities between empirical research and string theory: string theory connects quantum-mechanics (for an introduction of the field to scholars of literarature, see Zajonc) and the theory of relativity (Einstein) - considered incompatible before-by supposing complementary curled up space dimensions under the Planck length as suggested first by Theodor Kaluza in 1919 (see Salam and Strathdee). Empirical research can take into account the multiplicity of kinetic spaces which can be regarded as a multiplicity of time dimensions. If I deliver a presentation, I read literature, I pray, I train my muscles or practice anything else: such does not happen only in a location determinable by measurable coordinates, but also in the space of a happening having its special rhythm. The space of gestures is never a four-dimensional space-time only. What is measured by the observer in a four-dimensional space-time is completed empirically by a rhythmic dimension. The question is not only where and when something is happening and what is going on in the measurable space and time, but also in which rhythmic or kinetic space it occurs. Time as the space of movement is not only (measurable) duration, but rhythm as well. In the terms of string theory, we have to take into consideration two time dimensions. More exactly, we need to consider that occurrences with special rhythms have their own times and that we have to deal with many complementary time dimensions. Thus, rhythm is two-dimensional time, but every rhythm has different complementary dimensions. The complementary space dimensions of string theory are of extremely small size (under the Planck length, shorter than $10^{-33} \mathrm{~cm}$ ). They require a technological precision in measurement which is at the moment (and surely will remain for a long time) unreachable. Similarly, in the case of extra time-dimensions we need extremely refined, but possible gestures of attention. Without such precision of attention they remain out of reach or they will be perceived as being reduced to other time dimensions or to the extended historical dimension, for instance. Literary or other artistic practices are intensive enough to observe occurrences which are not happening in physical or historical time, but in the kinetic spaces or rhythmical dimensions of extremely refined attentive gestures.

We can conceive of the curled-up time-dimensions as the duration of a rhythm folding back into itself. As the vibration pattern of a string is an occurrence turning back into itself, the rhythm of a practice also has a complementary curled up time-dimension. The vibration pattern of a string can change, in principle, but only under such extreme circumstances as the Big Bang. Only the gestures of attention make possible multiple shifts among different resonance patterns. So, we have to make a distinction between the process of the occurrence in the extended time-dimension and the extra curledup time dimensions of gestures which can be conceived of as "Calabi-Yau" kinetic spaces (for samples of Calabi-Yau shapes see Greene, Elegant 96). According to string theory, the features of experimentally confirmed elementary particles (their mass and force charge) depend on the vibration pattern their inner strings perform (Greene, Elegant 69). We can reveal a further affinity between string theory and empirical research by considering that practice is conceived of by the latter as resonance patterns and rhythms of gestures of attention. If strings are the last level of reality, empirical research considers gestures to be the ultimate reality of motion. If we can define gesture as the resonance pattern of attention, the special vibration of a string can be regarded in turn as an elementary physical gesture. We could probably lay the foundations of practice-oriented physics tailored on rhythm by this connection between the string and gesture. As the special vibration pattern of a string corresponds to the graviton (the smallest force transmitter of gravity), gesture is the quantum of practice. Not only attention, but movements of any behavior in the broad sense can be regarded as gestures beginning with the vibrations of strings to the gestures of literary reading and writing. Since we are speaking here about movements strictly irreducible to one another, there is no need to worry about practice-oriented research tailoring physical phenomena to its patterns by the introduction of the broad sense of "gesture." This proposal itself is a gesture of being open toward any kinds of movements including physical ones.

If the reductionist view of the world speaks about the (biological, chemical and physical) substrata of our behavior, why not to propose the behavior of the substrata including the behavior of strings, electrons, or quarks (see Greene, Elegant 12) as the focus of practice-oriented research. I do not assimilate or domesticate the vibration patterns of strings into my own research because it is enough to argue that reductionism does not show us how the world works; rather, it reveals the practice of scholars who resonate with the happenings of the world in this manner and hence reduction is ultimately their gesture of contact-making. This relativistic approach to movement, however, implies more than an equality of inertial frames of reference: the inequality of the multiple space and time dimensions of 
gestures as well. If string theory makes a connection between the theory of general relativity and quantum mechanics, practice-oriented research links physics, the humanities, and the social sciences inasmuch as it approaches them as orientation practices in space-times conceived of as kinetic spaces.

4) The hither and thither side of analogy: it is true that curled-up dimensions of practice-oriented research are not mathematical ones, but analogies of curled-up space dimensions of string theory. The basic difference, however, is that curled-up time dimensions cannot be described mathematically. Henceforth the analogy turns into asymmetry: the extra space-dimensions cannot be reached by our senses (not even by our imagination), but only by mathematics and unlike extra time-dimensions, which can be accessed by our practices, but not by mathematics. Mathematics, as all other forms of practice can only move within the frames of its own complementary kinetic space (and no other). The impossibility of a mathematics of extra time dimensions results from the fact that curled-up rhythmical dimensions are practically unequal, incompatible, and without compatibility calculations are rendered impossible. Mathematical interchangeability supposes always the same equality to avoid being dislodged from the algorithm of equations. However, unfortunately practices can be (inter)changed only by a change of rhythm in one's practicing. Why is it impossible to calculate the rhythm of motion? Because calculation reduces the dimensions of occurrences to extended and curled-up space dimensions and to one extended time dimension. Just as our imagination reduces Calabi-Yau shapes having more than three dimensions to two- or at most three-dimensional forms. Mathematics, thus, cannot grasp rhythms (except those of algorithms) because they are not symmetric. Instead of symmetry and commutativity so important for mathematics and physics, here we are confronted with the dominance of asymmetry. More exactly, the asymmetry of kinetic spaces stands against the relativistic symmetry of vantage points (frames of reference) established by Einstein's equations. We have to deal with the difference between two practical orientations, that is, between the symmetric and the asymmetric orientation which can never stand on the two sides of an equation. We can create contact between them only by a passage from one practice to the other or back and this implies that we orient ourselves in an asymmetrical way. What is true for calculation is also true for measuring, because measuring is based again on equation. The curled up rhythmic dimensions cannot be grasped by measurement either, since it can create practical contacts only within its own rhythmic dimension. This is why I have suggested to my physicist acquaintances to extend experiments beyond the kinetic spaces of measurement and calculation. The theory of relativity, quantum-mechanics and string theory contributed considerably to a radical change in the classic notion of space and time; now it's the time for challenging the measurable and calculable space-time itself. Physical measurement and calculation cannot access the rhythmic dimension of space-time, just as, in an asymmetric way, literary reading and writing cannot access the realm of physical measurements and calculations. But are then the rules of different kinetic spaces the same? The study of physical worlds of different scale has its own limits: in the cosmic world investigated by the theory of general relativity there is the limit of the light speed and the slightly curved space-time fabric. The "middle" world of quantum-mechanics has its limits in Heisenberg's Uncertainty Principle: we cannot measure the position and the momentum of elementary particles simultaneously (see Greene, Elegant 54-56). Finally, in the super-microscopic world of string theory the main limit is the technologically unreachable Planck length (Greene, Elegant 62-63).

I am skeptical about the "theory of everything" (e.g., the M-theory version of string theories [see Greene, Elegant 129-45]) because the ultimate rules of motion cannot be grasped in kinetic spaces. There is no way to avoid practical orientation of which theoretical physics is only one. The quantum phenomena under the Planck length are not the only things that cannot be measured. Empirical occurrences are similarly beyond measurability. We have to deal not only with the scale limits of measurement, the kinetic or rhythmic space of measurement also has its own limits. In practice, one has to free oneself from the limitations of measurement and calculation in order to get closer to the events occurring in other kinetic spaces, otherwise they are simply inexistent in the same way as the quantum jittery is for the geometrical space-time fabric of general relativity (see Greene, Elegant 74). A theory of everything cannot reduce everything to one complex space; rather, we should consider everything at its practical or rhythmic scale. Kinetic spaces (including those of strings) are more spacious than any complex space because there is a practical limit in their incorporation. Although we have unmasked the analogies, there is still one Heisenberg-analogy left. As it is impossible to measure the position and momentum of elementary particles simultaneously, hence no one can research calculable processes and gesture resonance at the same time (dimension). Nevertheless, everyone can cross the practical distance between the two by changing the rhythm of his/her gestures.

5) The topicality of Plato's cave experiment: according to Plato, just as chained prisoners facing the blank wall of a cave see nothing, but the projected shadows of things moving behind them in the light of fire, our empirical experiences provide us, similarly, with distorted pictures about the truth of ideas (see Plato 747-50). If we project Plato's cave experiment onto the dimensions of rhetoric interpretation, it appears to be an allegory that reflects in an accidental or contingent way Plato's formula, a conception one could hardly take seriously today with its ideas seen as autonomous beings. However, turning this image into an experiment by realizing its relevance regarding the problems of projections and dimensions, it is not only working, that is, executable, but it also leads to conclusions compatible with contemporary string theory. Plato proved with his cave experiment that creating a projection having fewer dimensions than the projected event means serious loss of happening. From this one might infer that the world is probably more than what one can perceive in geometric space (tailored ultimately to the motion of light) and in measurable/countable time. Contingency or accidental events often occur when one tries to calculate what is going on by using a projection with fewer dimensions: when one explains, for instance, literary writing and reading through its social historical projection or a ritual by its socialphysical projection (see Néda, Ravasz, Vicsek, Brechet, Barabási). What remains outside of such social historical or social-physical phenomena-the gestures of attention of literary writer and reader, the faith 
of pilgrims or the ritual "know-how" of the theater audience-are excluded as contingent, accidental, or particular circumstances. However, what is overlooked may return as a surprise: if we follow, for instance, the shadow of an approaching person on a white sheet hanged between the person and us, we expect the person to appear soon. But if the person holds a sword which could not be detected on the two dimensional projection, it will be a surprise when the person shoves aside or pierces the sheet with the sword.

The number of dimensions depends on the possible directions of movement. If we start from the most evident space directions we come to realize that a direction in time is different, although it is familiar to speak about moving back and forth in time. In fact, the only connection between space and time directions is that we regard them as measurable and countable quantities (i.e., we measure and calculate them both). Albeit this way of dealing with space and time is largely accepted, it remains problematic because it excludes many kinds of occurrences, everything except "physical" phenomena. Among others, biological and social rhythms, artistic practices, or the movement of thought itself remain out of notice. How many possible directions are there if my attention moves? I suggest that we need to consider that it is always directed to something. String theory assumes many complementary curled-up space dimensions beyond the three extended ones, but preserves the only and one-directional time dimension. Again, I wonder in how many directions one can move in time? Taking into consideration that time is not only measurable duration but rhythm as well, beside its passing we have to deal with different rhythmic directions, too. But this time direction ceases to stretch along a straight line, it becomes the rhythm of a movement and, consequently, changing the direction is equal to changing the rhythm. This allows us to assume an unlimited number of rhythmic dimensions as the every-day extensions of the four dimensional space-time of physics. This is why attention can move in so many directions: it can turn in a direction of classic geometrical space, it can be focused on objects of different scale and nature. Physicists, for instance, can investigate elementary particles, celestial bodies, or small objects sliding on a slope; biologists may turn their attention towards the inner structure of a cell and to the anatomy of organs or hormonal functions; and scholars of the humanities towards reading and writing practices, etc. But there is a further issue to consider here: attention moves in different ways while measuring and calculating physical movements, while mapping biological processes or while following literary reading and writing practices; moreover, it may move in different ways even within this last realm.

Having in principle an unlimited number or uncountable complementary rhythmic dimensions entails that practices including calculation and measurement are limited to their own complementary rhythmic dimensions. Thus, by reducing the diverse practices of attention to the dimensions of physical spacetime or to the complementary rhythmic dimensions of measurement and calculation, we project a multidimensional motion to a kinetic space with less dimensions and limit our further investigation to the movements of this projection. Statistical estimation is also a reductive projection of this kind, acceptable only from the point of view of measurable and countable processes of one investigated direction, because it leaves out of consideration all other rhythmic dimensions of the investigated occurrence. With reference to rhythm, it is different to predict or to follow an event. We can estimate by calculation that the Titanic will sink as a consequence of the collision with the given iceberg at the given speed. We also can predict that this will trigger fear and panic among its voyagers. But if we are interested in how exactly this event takes place we have to follow it in a different manner: for instance by writing a screenplay, by directorial and actorial work, by shooting the film, or by watching it. Should we try to reduce all these to statistical estimation saying that even the director and actors make predictions concerning what is probable in a given situation or should we distinguish between statistical estimation which has a predictive power, but covers the density of an event and artistic practices that follow the rhythm of the happening? In my view, this is a physical difference as well, since statistical estimation and artistic practices have their own curled-up dimensions and events occurring in one realm can be projected onto the other only by considerable distortions. If we use metaphors-a practice that physicists try to avoid-we distort physical phenomena, for instance considering rhythms time dimensions. It would be useful to debate this issue in order to find out whether rhythm is really a dimension or not by investigating the projection of physics onto literature/culture and the projection of literature/culture onto physics. According to my arguments, social physics would be a discipline that could describe rhetoric replacements used for instance by a practitioner of a contextual approach who regards nocturnal wandering in a mountain forest as a social historical product or by a literary scholar who regards rhythm as time dimension, as projections not in the space-time based on the Euclidean geometrics, but in the multidimensional time of the "Calabi-Yau" spaces of motion.

6) Rhythmic dimensions and time projections: a physical model of the pilgrimage to the Kaaba Stone in Mekka limits itself to the movement of human bodies characterized by mass and extension in space, while it seems to describe a social and religious event. The physical model for the rhythmic applause follows a calculable change in the tempo of clapping palms, while it seems to reduce the rhythm of a theater ritual to physical rules (see Néda, Ravasz, Vicsek, Brechet, Barabási, "Physics," "Selforganizing"). From this sociophysical point of view it is accidental that the pilgrims are praying just as the fact that ants moving according to the same rules are gathering food, and that the pellets of a physical experiment have nothing in mind, but move similarly in a narrow space. The dimensions reduced by a projection become accidental. The point for us is not to decide if there is an objective contingency there or just a methodological one. Even the deterministic world has more than one predictable trajectory: there are many directions and what is going on in one of them cannot be derived from the other. Our freedom to take directions is designed by the need to orientate ourselves in a "forest" of multiple urgings and impulses. Beyond our innate abilities, it depends on practice what kind of impulses we can follow and how we learn to orientate ourselves in and between these rhythmic directions. If we reduce complex but deterministic phenomena by introducing the methodological accidental, we leave 
out of consideration and fail to follow the density or rhythm of happenings and this is tantamount to saying that we project them to the physical space-time and by this to the kinetic spaces of certain attention practices (measurement and calculation) as complex but, in principle, deterministic phenomena. If we remove a rhythmic dimension by projection, most of the happenings pertaining to that dimension become accidental for us, because they are incalculable, unexplained, or maybe imperceptible within the dimensions of the projection. The models offered by sociophysics do not follow a socialreligious or theatrical-cultural occurrence, but give us projections onto the complementary dimensions of measurement and calculation. This is why the resulting phenomena are necessarily reduced and different from those happening in the complementary dimensions of the religious or theatrical ritual although both versions of events might have common extended dimensions.

I do not dismiss the experiments and models of sociophysics. On the contrary, I consider them important contributions to the exploration of rhythmic dimensions. But according to their results, including those of Plato's "sociophysical" experiment, we should not conclude that everything that is real must occur in physical space-time. Instead, we ought to draw the conclusion that orienting ourselves exclusively in the physical space-time means to project everything into its restricted dimensions. But there are other time dimensions beyond the physical one, which I call "rhythmic dimensions." Should scientific disciplines not be considered just different kinetic spaces for our attention practices? We can investigate rhythmic applause as a chemical, biological, psychological, social, cultural, political, economical, or religious event. Should we say that rhythmic applause has these many dimensions? Of course, we may say that it is a complex process that calls for multiple ways of investigation, but what do we mean here by "complex" and by "multiple" ways of investigation? Does "complex" mean that everything takes place in the same four-dimensional space-time and within these dimensions everything should be seen as connected? Are the multiple ways of investigation possible within the frames of these four dimensions, even though we have just enumerated twice as many disciplinary perspectives? What does it mean to approach rhythmic applause from the point of view of different disciplines? Does it mean to follow different rhythms every time? Does our disciplinarily trained attention have to orientate itself in different rhythmic dimensions whenever we change the direction? If taking into consideration also the complementary rhythmic dimensions of measurement and calculation, we must conclude that even these operations have more than four dimensions because the attention practices they call for are not limited to physical space-time.

Are there extended dimensions at all or they are only happenings projected onto the complementary curled up dimensions of measurement and calculation which themselves are extended to the extent they are projected onto the infinite number axis? If a curled-up time dimension is the duration of a rhythm folding back into itself, it cannot be extended infinitely, it is valid only for the kinetic space of that particular rhythm just as complementary space dimensions are curled up according to string theory. It seems to me that physics is tailored not only to light, but to the infinite scale of numbers as well. Maybe the only extended dimension we know is the axis of numbers to which we project space and time as relations of quantity by measurement and calculation. The space and time dimensions of our coordinate system are extended as well by being projected onto the straight line of this axis. According to string theory, it is possible that in the existing space every straight line is curled up and we regard them as infinitely straight because of their immeasurable size (see, for instance, the "U-shaped universe" model in Greene, Elegant 120). If we say that something cannot be measured, we do not refer to the extension of a dimension alone. It may also mean that it is not possible to get into any complementary rhythmic dimension by measurement and calculation. Cleverly designed mathematical and physical experiments can help us to grasp projections to a space-time which itself is projected to the infinite axis of numbers. Such projections of projections are not so far from the multiple distortions Plato described. This realization about curled-up time dimensions leads not only to the idea of physical relativity, but it compels one to practical orientation as well. It is no longer sustainable that the four-dimensional space-time is a limit for us, since the urge for practical orientation springs from the possibility to become practiced in many other complementary rhythmic dimensions. But practicing measurement and calculation we cannot get into rhythmic dimensions which do not match each other, i.e. which are not projected onto the same infinite number axis. Take, for instance jugglers' tricks which amaze us. Our surprise over their stunts which seem marvelous, often stems from the fact that the artful mastery of the juggler displaces our attention from several rhythmic dimensions. Although something "complex" is happening before our eyes, we only see its projection with fewer dimensions. Let us take part in a scientific experiment concerning attempts to distract our attention following Daniel Simons's instructions in the experiment called "Monkey Business Illusion" <http://www.dansimons.com/videos.html>). If one keeps counting how many times the players wearing white pass the basketball, most often the viewer does not observe other happenings.

If it seems to us that there are more and more accidental or incalculably singular events taking place around us, it would be recommended to think over our culturally dominant orientation practices including scientific research methods. It is a scientific requirement to define our models/projections concerning investigated phenomena clearly, but individual disciplines are tuned to different rhythms according to the complementary curled up rhythmic dimensions of their experimental practices and that cannot be harmonized into a single, howsoever complex space. From this point of view, the only difference between sciences and arts is that the sciences try to remain in the space with the same disciplinarily chosen dimensions, while art finds passages back and forth between different spaces of motion. Hence artistic experiments make us experience and gain practice in multiple complementary curled-up dimensions. These two ways of orientation cannot be derived from each other. I call the former "symmetric" because it clings to the interchangeability of dimensions by rotation and I call the latter "asymmetric" because of its incommensurable rhythmical dimensions. We are faced with the proliferation of accidental events and incalculable singularities mostly because asymmetric orientation is largely ousted by the symmetric 
one. The complex, but reductive space-time domination of our world view is to be enlarged towards the spaciousness of different complementary space and time dimensions.

7) Toward the experiments of practice-oriented physics: I posit that we need to design experiments and models of inquiry which make practice-oriented physics research possible. Such an approach is characterized by its capacity to differentiate among mathematical algorithms and other practical rhythms without converting them rhythmically. This way, we research parallel kinetic spaces with different time dimensions between which calculable relations (of a limited space-time) will never open up a passage. This becomes possible only by practical contact-making or gestural orientation. The general theory of relativity is still too special and in order to complement it, we have to introduce the principle of practical relativity into physics: beside the speed of one observer-experimenter relative to other observer-experimenters, the kinetic spaces they are practicing in should also be taken into consideration. Thus we would be following different rhythms when we are measuring and calculating space-time relations and when we pay attention to the weather as the-walk-of-times (see Bodor's literary experiment; see also Berszán, Gyakorláskutatás 220-34.) I make this proposal of establishing the discipline of practice-oriented physics in a situation when the impossibility of measurement and experimentation endangers physics in one of its top branches and threatens to turn its space into purely mathematical space, namely the abstract space-time of calculation and geometry. Beyond their affinities there is only one main (and fortunately gratifying) difference between string theory and empirical research: while string theory at the moment belongs to the category of belles-lettres, that is, mathematical fiction because owing to the insufficiency of present day technological precision no experimental (empirical) evidence is available only its "mathematical aesthetics," empirical research is in turn an "experimental science." "Plucking" the strings under the Planck length is yet impossible in practice, but in empirical research it is possible to "pluck" the strings of attention. For this reason, I posit that in physics besides mathematical research we ought to do projects in practice-oriented physics as well. I suggest the same to the humanities and social sciences including media theoretical and social historical investigations of literature focusing only on a re-thinkable contextual approach. The project would be about the rhythm of particles, stars, galaxies, cells, organs, and machines including extra time-dimensions of their kinetic spaces. The missing historhythm Henri Lefebvre discusses in his Rhythmanalysis: Space, Time and Everyday Life could be recovered in kinetic spaces. What appears to be in the extended dimension of historicity, a construction explicable by the operation of different contexts can be re-discovered with rhythmic precision as occurring in complementary time dimensions.

\section{Works Cited}

Barabási, Albert László. Linked: The New Science of Networks. Cambridge: Perseus, 2002.

Berszán, István. Gyakorláskutatás (Research on Practice). Bratislava: Kalligram, 2013.

Berszán, István. "Historical Criticism: Orientation in Time(s)." Orientation in the Occurrence. Ed. István Berszán. Cluj: Komp, 2009. 193-205.

Berszán, István. "Irodalomfizika, avagy átjárhatnak-e a diszciplínák határain az angyalok? ("Literary Physics: Are Angels able to Cross over the Borders of Disciplines"). Paradigma(váltás) és kommunikáció (Paradigm[Shift] and Communiçation). Ed. Zsolt Lázár, Zssolt József, and Károly Veres. Cluj: Egyetemi Múhely, 2014. 63-76.

Berszán István. "Ismétlés-e a gyakorlás? A megfigyelt és a követett ritmusról ("Regular Recurrence or Practice? About Rhythm as Observed and Followed"). Tiszatáj (2016.01.15.): <http://tiszatajonline.hu/?p=91414>.

Berszán, István. "Rendszeridő és kísérlet a fizikában és az irodalom(tudomány)ban" ("System Time and Experimentation in Physics and Literature"). Az idő́ paradoxonai (Paradoxes of Time). Ed. Gyöngyi Orbán, András Borbély, and Zalán Serestély. Cluj: Egyetemi Múhely, 2015. 303-15.

Bodor, Adám. Verhovona madarai (The Birds of Verhovina). Budapest: Magvető 2011.

Einstein, Albert. The Special and General Theory. Trans. Robert W. Lawson. London: Methuen \& Co, 1920.

Greene, Brian. The Elegant Universe: Superstrings, Hidden Dimensions, and the Quest for the Ultimate Theory. New York: Norton, 2003.

Greene, Brian. The Hidden Reality: Parallel Universes and the Deep Laws of the Cosmos. New York: Random House, 2011.

Kertész, Imre. Fatelessness. Trans. Tim Wilkinson. New York: Knopf, 2004

Kittler, Friedrich. Optical Media: Berlin Lectures. Trans. Anthony Evans. Cambridge: Polity P, 2010.

Lefebvre, Henri. Rhythmanalysis: Space, Time and Everyday Life. Trans. Stuart Elden and Gerald Moore. London: Continuum, 2004

Müller, Herta. The Hunger Angel. Trans. Philip Boehm. London: Portobello, 2013.

Néda, Zoltán, E. Ravasz, T. Vicsek, Y. Brechet, and A-L. Barabasi. "Physics of the Rhythmic Applause." Physical Review E'61.6 (2000): 6987-92.

Néda, Zoltán, E. Ravasz, T. Vicsek, Y. Brechet, and A-L. Barabasi. "Self-organizing Processes: The Sound of Many Hands Clapping." Nature 403 (2000): 849-50.

Plato. Republic. Trans. P. Shorey trans. New York: Random House, 1963.

Salam, Abdus, and J. Strathdee. "On Kaluza-Klein theory". Annals of Physics 141.2 (1982): 316-52.

Simons, Daniel. "Surprising Studies of Visual Awareness." dansimons.com (2003): <http://www.dansimons.com/videos.html>.

Wu, Wayne. Attention. London: Routledge, 2014.

Zajonc Arthur, ed. The New Physics and New Cosmology: Dialoges with the Dalai Lama. Oxford: Oxford UP, 2004.

Author's profile: István Berszán teaches literary theory and comparative literature at Babeș-Bolyai University. His interests in scholarship include empirical and practice-oriented research of literature and culture and physics. In addition to numerous articles, Berszán's single-authored book publications include Terepkönyv. Az írás és az olvasás rítusai. Irodalmi tartamgyakorlatok (2007) (Rites of Writing and Reading: Exercises in Duration of Practice) and Gyakorláskutatás (2013) (Research on the Investigation of Practice), and the collected volume Orientation in the Occurrence (2009). E-mail: <berszan.istvan@ubbcluj.ro> 